\title{
Development and validation of a self-report version of the Spinal Cord Independence Measure (SCIM III)
}

\author{
C Fekete ${ }^{1}$, I Eriks-Hoogland ${ }^{1,2}, \mathrm{M}$ Baumberger ${ }^{2}, \mathrm{~A} \mathrm{Catz}^{3}, \mathrm{M}$ Itzkovich $^{3}, \mathrm{H} \mathrm{Lüthi}^{4}, \mathrm{MWM} \mathrm{Post}^{1,5}$, \\ E von Elm $^{6,7}, \mathrm{~A} \mathrm{Wyss}^{2}$ and MWG Brinkhof ${ }^{1,8}$
}

\begin{abstract}
Study design: Cross-sectional validation study.
Objectives: To develop and validate a self-report version of the Spinal Cord Independence Measure (SCIM III).

Setting: Two SCl rehabilitation facilities in Switzerland.

Methods: SCIM III comprises 19 questions on daily tasks with a total score between 0 and 100 and subscales for 'self-care', 'respiration \& sphincter management' and 'mobility'. A self-report version (SCIM-SR) was developed by expert discussions and pretests in individuals with spinal cord injury (SCI) using a German translation. A convenience sample of 99 inpatients with $\mathrm{SCl}$ was recruited. SCIM-SR data were analyzed together with SCIM III data obtained from attending health professionals.

Results: High correlations between SCIM III and SCIM-SR were observed. Pearson's $r$ for the total score was 0.87 (95\% confidence interval ( $\mathrm{Cl})$ 0.82-0.91), for the subscales self-care 0.87 (0.81-0.91); respiration \& sphincter management 0.81 (0.73-0.87); and mobility $0.87(0.82-0.91)$. Intraclass correlations were: total score $0.90(95 \% \mathrm{Cl} 0.85-0.93)$; self-care $0.86(0.79-0.90)$; respiration \& sphincter management $0.80(0.71-0.86)$; and mobility $0.83(0.76-0.89)$. Bland-Altman plots showed that patients rated their functioning higher than professionals, in particular for mobility. The mean difference between SCIM-SR and SCIM III for the total score was 5.14 (point estimate $95 \% \mathrm{Cl}$ 2.95-7.34), self-care 0.89 (0.19-1.59), respiration \& sphincter management 1.05 $(0.18-2.28)$ and mobility $3.49(2.44-4.54)$. Particularly patients readmitted because of pressure sores rated their independence higher than attending professionals.
\end{abstract}

Conclusion: Our results support the criterion validity of SCIM-SR. The self-report version may facilitate long-term evaluations of independence in persons with $\mathrm{SCl}$ in their home situation.

Spinal Cord (2013) 51, 40-47; doi:10.1038/sc.2012.87; published online 14 August 2012

Keywords: SCIM; spinal cord injury; validation study; outcome measures; activities of daily living

\section{INTRODUCTION}

The Spinal Cord Independence Measure (SCIM), which was first published in $1997,{ }^{1}$ has become a widely used instrument to measure functioning in activities of daily living in persons with spinal cord injury (SCI). ${ }^{2}$ Its main advantages over other instruments used for functional assessment in rehabilitation medicine are its sensitivity to changes in performance of tasks that are relevant for SCI patients, and the fact that it measures not only the burden of care, but also achievements, which have medical, psychological or social relevance for the SCI patient. The third version of the instrument, SCIM III, has been tested for validity and reliability in multicenter studies with satisfying psychometric properties. ${ }^{3-5}$

SCIM III comprises items on 19 daily tasks grouped into three subscales. Item scores are weighted according to their clinical relevance and are graded for increasing difficulty, that is, requiring higher ability of the person with SCI. Each item has between 2 and 9 grades. The total SCIM III score ranges between 0 and 100, higher scores reflecting higher levels of performance or independence of a person. ${ }^{3}$ The three subscales assess the areas of 'self-care' (six items, range 0-20), 'respiration \& sphincter management' (four items, range $0-40$ ) and 'mobility' (nine items, range $0-40$ ).

SCIM III is scored in observation of persons with SCI by health professionals. Ideally, each subscale is scored by clinical staff experienced in the assessment of the activities covered by the subscale. Such observations are time consuming and mainly applicable in inpatient settings. ${ }^{6}$ In the outpatient setting, SCIM III data were collected by a single rater or in interviews previously, although with slightly decreased precision. ${ }^{7,8}$ For research purposes, SCIM data are obtained by interview as part of the regular follow-up of large international studies, such as the European Multicenter Study about Spinal Cord Injury (EMSCI). ${ }^{9}$

Studies conducted in the SCI community usually rely on selfadministered questionnaires for data collection. This method requires comparatively few resources, provides fast data collection and is applicable independent of the setting. ${ }^{6,10}$ Using self-report questionnaires for continued monitoring of daily activities in community-dwelling persons with SCI might allow detecting special health care needs in this population.

${ }^{1}$ Swiss Paraplegic Research, Nottwil, Switzerland; ${ }^{2}$ Swiss Paraplegic Center, Nottwil, Switzerland; ${ }^{3}$ Spinal Rehabilitation, Loewenstein Rehabilitation Hospital, Raanana, Tel-Aviv University, Tel-Aviv, Israel; ${ }^{4}$ Swiss Paraplegic Center REHAB Basel, Basel, Switzerland; ${ }^{5}$ Rudolf Magnus Institute of Neuroscience and Centre of Excellence in Rehabilitation Medicine, University Medical Center Utrecht and De Hoogstraat, Utrecht, The Netherlands; ${ }^{6}$ Institute for Social and Preventive Medicine, Lausanne University Hospital, Lausanne, Switzerland; ${ }^{7}$ German Cochrane Centre, Department of Medical Biometry and Medical Informatics, University Medical Centre, Freiburg, Germany and ${ }^{8}$ Department of Health Sciences and Health Policy, University of Lucerne, Lucerne, Switzerland

Correspondence: Dr C Fekete, Swiss Paraplegic Research, Guido A. Zäch Strasse 4, 6207 Nottwil, Switzerland.

E-mail: christine.fekete@paranet.ch

Received 27 April 2012; revised 5 June 2012; accepted 7 June 2012; published online 14 August 2012 
An internal review showed that the SCIM III covers most of the relevant categories in the field of activities and participation defined in the International Classification of Functioning, Disability and Health (ICF) Core Sets for SCI. ${ }^{11,12}$ An efficient measurement of predefined relevant ICF categories in epidemiologic studies is highly important. ${ }^{13}$ For the community survey of the Swiss Spinal Cord Injury Cohort Study, ${ }^{14}$ a self-report version of SCIM III (SCIM-SR) was thus needed. Besides the advantages for community-based research, a self-report version might also help reduce the time and effort required for administration in routine care. Therefore, SCIM-SR provides an important additional tool for assessing patients' daily task performance.

The aim of this study was to assess the criterion validity of SCIM-SR by comparing it to the SCIM III assessment by health professionals.

\section{MATERIALS AND METHODS}

\section{Subjects}

Between July and December 2011, we recruited 100 persons aged over 18 years who attended the inpatient clinics of the Swiss Paraplegic Center Nottwil and REHAB Basel (Switzerland) in a convenience sample. Eligible participants needed to have traumatic or non-traumatic SCI (time since injury $\geqslant 1$ month), sufficient German language skills (assessed by clinical staff) and the ability to read and answer the self-report questions by themselves. Persons with severe health conditions or cognitive impairments as well as those who underwent surgery in the previous 7 days were excluded. Informed consent was obtained from all study participants.

\section{Procedure}

Study participants were asked to fill in a paper-pencil version of the SCIM-SR questionnaire. In case the participants had difficulties to write because of limited hand function, a researcher helped with completion but did not explain items or help choose an answer. Attending health professionals (including occupational therapists, physiotherapists and nursing staff) completed the German SCIM III by observation of the participants. ${ }^{3}$ While SCIM III is routinely used at the Swiss Paraplegic Center Nottwil by a team of staff members familiar with the care of SCI patients, this is not the case at REHAB Basel. In this center, SCIM III was completed by a physician with experience in SCIM III in collaboration with the nursing staff in charge. The German version of SCIM III has been developed by members of the EMSCI study at the University clinic of Balgrist (Switzerland) and is routinely used in German-speaking clinical settings. The maximum delay between questionnaire completion by participants and health professionals was 4 days. Both were blinded to each other's scores. We certify that all applicable institutional and governmental regulations concerning the ethical use of human volunteers were followed during the course of this research.

\section{Instrument development}

On the basis of the English SCIM III, ${ }^{3}$ a preliminary English SCIM-SR version was developed. Three investigators familiar with SCIM III and experienced in questionnaire design independently drafted an adapted version for self-report. Using feedback of additional team members, the three draft versions were combined into a single harmonized draft version of SCIM-SR. Briefly, the wording of the 19 items was adapted by using personal pronouns and avoiding or explaining technical terms. For item 6 (bladder management), we omitted the criterion of residual urine volume because this information is usually not known by persons with SCI. Several complex items or response categories were decomposed to facilitate self-reporting. This included SCIM III items with several statements in one answering option (items 6 and 7) or with more than six answering options (items 5, 12-14). Scoring algorithms were developed to obtain scores from these decomposed items that are consistent with SCIM III scores.

External experts with expertise in SCIM III and the developer of SCIM III reviewed the harmonized version for face validity. On the basis of their feedback, it was revised further and translated into German by professional scientific translators.

The German draft version was then pretested in cognitive interviews with five persons with SCI. Additionally, five German-speaking experts who routinely use SCIM III in the clinical setting were asked for feedback. Overall, the pretests showed that the SCIM-SR was understandable and acceptable. However, results of the cognitive interviews indicated that participants were confused by some descriptions and definitions, and these were omitted. Also, other minor modifications were made. The final German version of the SCIMSR was then translated into English (Appendix), French and Italian.

Furthermore, information on age, gender, years of formal education, date of injury and para-/tetraplegia was collected in the paper-pencil questionnaire. Information on completeness of lesion and reason for hospitalization was retrieved from the medical records.

\section{Statistical analyses}

Pearson's correlation coefficients were computed to analyze associations between SCIM III and SCIM-SR. Further, intraclass correlations (ICCs) were calculated to quantify the agreement between SCIM III and SCIM-SR scores. ICC take into account systematic differences in assessments that are not reflected in ordinary correlations such as the Pearson's correlation. ${ }^{15}$ The Bland-Altman method was used to report on differences between SCIM III and SCIM-SR scores by calculating the mean difference between the two measurements. ${ }^{16}$ BlandAltman plots were used to depict the difference in SCIM-SR and SCIM III scores against the mean score of both measurements for each subject.

For sensitivity analyses, stratified mean differences between SCIM III and SCIM-SR scores were calculated and linear regressions were run. In regression analysis, we used the mean differences between the two scores as continuous outcome and regressed it on selected independent variables. Unadjusted and adjusted coefficients and their $95 \%$ confidence intervals (CIs) were computed. For the regression models, predictors were either introduced as categorical (age, education and reason for admission) or dichotomous variables (gender, lesion characteristics and assistance with completion of the questionnaire). Likelihood-ratio tests were performed to assess significance of associations between predictors and outcome in regression models.

One case with an incomplete SCIM III score was dropped from the database. We used multiple imputation to account for missing data in the analysis. ${ }^{17}$ For details on imputation procedures see Supplementary Electronic Appendix. Data were analyzed using STATA 12.0 (College Station, TX, USA).

\section{RESULTS}

Characteristics of the study population are presented in Table 1.

Table 1 Characteristics of the study population

Total sample $(\mathrm{n}=99)$

\section{Sociodemographics}

Males, $n(\%)$

$73(73.7)$

Age in years, median (IQR)

$48.0(35.0-64.0)$

Formal education in years, median (IQR) [2]

$13.0(12.0-15.0)$

Lesion characteristics

Time post injury in years, median (IQR)

$0.7(0.3-18.2)$

Paraplegia, $n(\%)$

$53(53.4)$

Complete lesion, $n(\%)[3]$

$42(43.8)$

\section{Reason for hospitalization}

First rehabilitation, $n(\%)$

$54(54.6)$

Pressure sores, $n(\%)$

$19(19.2)$

Other, $n(\%)$

26 (26.3)

\section{Questionnaire completion}

Assistance with completion of questionnaire, $n(\%)$

29 (29.3)

Time needed to complete the SCIM-SR in minutes

$13.0(9.0-17.0)$

median (IQR) [25]

\section{Center of recruitment}

Swiss Paraplegic Center Nottwil, Switzerland, $n(\%)$

$93(93.9)$

REHAB Basel, Switzerland, $n(\%)$

$6(6.1)$

Abbreviations: IQR, interquartile range; SCIM, spinal cord independence measure.

Square brackets indicate number of missing values. 
Table 2 displays SCIM III and SCIM-SR scores. Mean and median values of the SCIM III were lower than those of the SCIM-SR. These differences were greatest in the subscale mobility. The range of the total score and the subscale respiration \& sphincter management was somewhat narrower in SCIM-SR than in SCIM III. Eight SCIM-SR total scores, six scores in respiration \& sphincter management, four in self-care and two in mobility were incomplete. We found most missing values in items $6(n=5), 3 \mathrm{~A}$ and $3 \mathrm{~B}(n=2)$. Items $1,2 \mathrm{~A}, 2 \mathrm{~B}$ and 9 had one missing each. The distribution of the total scores of SCIM III and SCIM-SR is shown in Figure 1.

Table 3 shows the Pearson correlations, the ICCs, the BlandAltman and the relative differences in means of SCIM III and SCIM-
SR. Pearson correlation coefficients for the total and the subscale scores ranged between 0.81 for the subscale respiration \& sphincter management and 0.87 for the total score and the subscales self-care and mobility. ICC values indicated coefficients ranging from 0.80 to 0.90. The highest ICC coefficient was observed for the total score, and the lowest for the subscale respiration \& sphincter management. In the Bland-Altman analysis, the largest difference between SCIM III and SCIM-SR was observed in the subscale mobility. The relative differences were highest in the subscale mobility and lowest in the subscale respiration \& sphincter management (Table 3 ).

Table 4 shows results for stratified differences and uni- and multivariable sensitivity analysis. Associations of differences in total

Table 2 Total and subscale scores of SCIM III and SCIM-SR

\begin{tabular}{|c|c|c|c|c|c|c|c|c|}
\hline & \multicolumn{2}{|c|}{ Total score } & \multicolumn{2}{|c|}{ Subscale self-care } & \multicolumn{2}{|c|}{ Subscale respiration \& sphincter management } & \multicolumn{2}{|c|}{ Subscale mobility } \\
\hline & SCIM III & $S C I M-S R$ & SCIM III & $S C I M-S R$ & SCIM III & $S C I M-S R$ & SCIM III & $S C I M-S R$ \\
\hline Total, $n(\%)$ & $99(100.0)$ & $91(91.9)$ & $99(100.0)$ & $96(97.0)$ & $99(100.0)$ & $94(94.9)$ & $99(100.0)$ & $98(99.0)$ \\
\hline Missing, $n(\%)$ & $0(0.0)$ & $8(8.1)$ & $0(0.0)$ & $3(3.0)$ & $0(0.0)$ & $5(5.1)$ & $0(0.0)$ & $1(1.0)$ \\
\hline Analyzed cases, $n(\%)$ & $91(91.0)$ & $91(91.0)$ & $96(96.0)$ & $96(96.0)$ & $94(94.0)$ & $94(94.0)$ & $98(98.0)$ & $98(98.0)$ \\
\hline Mean (s.d.) & $45.9(25.6)$ & $50.9(24.1)$ & $10.8(6.7)$ & $11.8(6.6)$ & $24.0(10.6)$ & $24.6(9.1)$ & $11.2(10.4)$ & $14.6(10.5)$ \\
\hline Median & 42 & 54 & 11 & 13 & 24 & 23.5 & 9 & 14 \\
\hline IQR & $9-94$ & 11-91 & $0-20$ & $0-20$ & $6-40$ & $10-40$ & 0-39 & $0-36$ \\
\hline Skewness & 0.36 & 0.07 & -0.14 & -0.53 & -0.13 & 0.09 & 1.16 & 0.63 \\
\hline
\end{tabular}

Abbreviations: IQR, interquartile range; SCIM, spinal cord independence measure; s.d., standard deviation; SCIM-SR, self-report version of SCIM III.
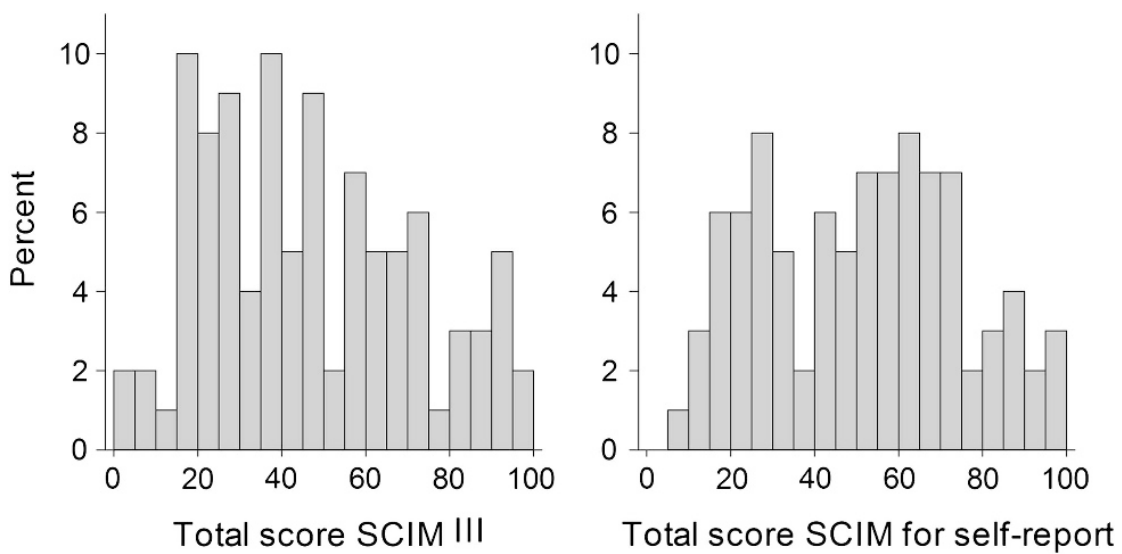

Figure 1 Relative frequency distribution of total scores of SCIM III and SCIM-SR.

Table 3 Pearson and intraclass correlation coefficients, Bland-Altman differences in means of SCIM III and SCIM-SR, and relative differences in total and subscale scores

\begin{tabular}{|c|c|c|c|c|c|c|}
\hline & \multirow{2}{*}{$\begin{array}{l}\text { Pearson correlation } \\
\qquad(95 \% \mathrm{Cl})\end{array}$} & \multirow{2}{*}{$\begin{array}{l}\text { Intraclass correlation } \\
\qquad(95 \% \mathrm{Cl})\end{array}$} & \multicolumn{3}{|c|}{ Bland-Altman difference } & \multirow[t]{2}{*}{ Relative difference (\%) ${ }^{\mathrm{a}}$} \\
\hline & & & Mean & $\angle O A$ & $\begin{array}{l}\text { Point estimate } \\
95 \% \mathrm{Cl}\end{array}$ & \\
\hline Total score & $0.87(0.82-0.91)$ & $0.90(0.85-0.93)$ & 5.14 & $-16.87-27.16$ & $2.95-7.34$ & 5.1 \\
\hline Subscale self-care & $0.87(0.81-0.91)$ & $0.86(0.79-0.90)$ & 0.89 & $-6.10-7.87$ & $0.19-1.59$ & 4.5 \\
\hline $\begin{array}{l}\text { Subscale respiration \& sphincter } \\
\text { management }\end{array}$ & $0.81(0.73-0.87)$ & $0.80(0.71-0.86)$ & 1.05 & $-11.26-13.36$ & $0.18-2.28$ & 2.6 \\
\hline Subscale mobility & $0.87(0.82-0.91)$ & $0.83(0.76-0.89)$ & 3.49 & $-7.07-14.05$ & $2.44-4.54$ & 8.7 \\
\hline
\end{tabular}

Abbreviations: Cl, confidence interval; LOA, limit of agreement; SCIM, spinal cord independence measure; SCIM-SR, self-report version of SCIM III.

Missing values were accounted for by multiple imputation.

aRelative difference $=$ Bland-Altman difference/maximum score of the scale $\times 100$. 
Table 4 Stratified differences and linear regressions on mean differences between total scores of SCIM-SR and SCIM III

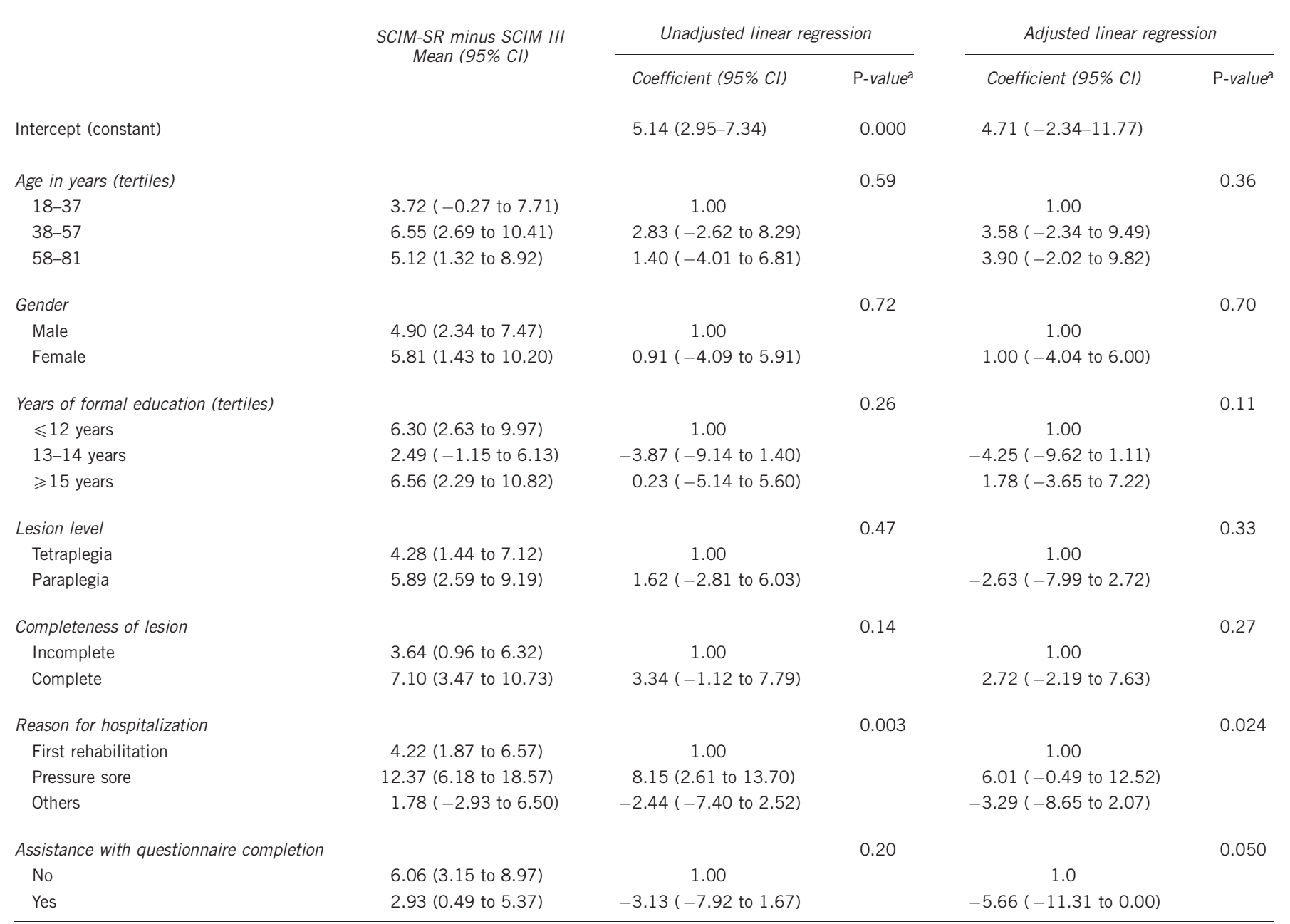

Abbreviations: $\mathrm{Cl}$, confidence interval; SCIM, spinal cord independence measure; SCIM-SR, self-report version of SCIM III.

Missing values were accounted for by multiple imputation.

a $P$-values from likelihood-ratio test.

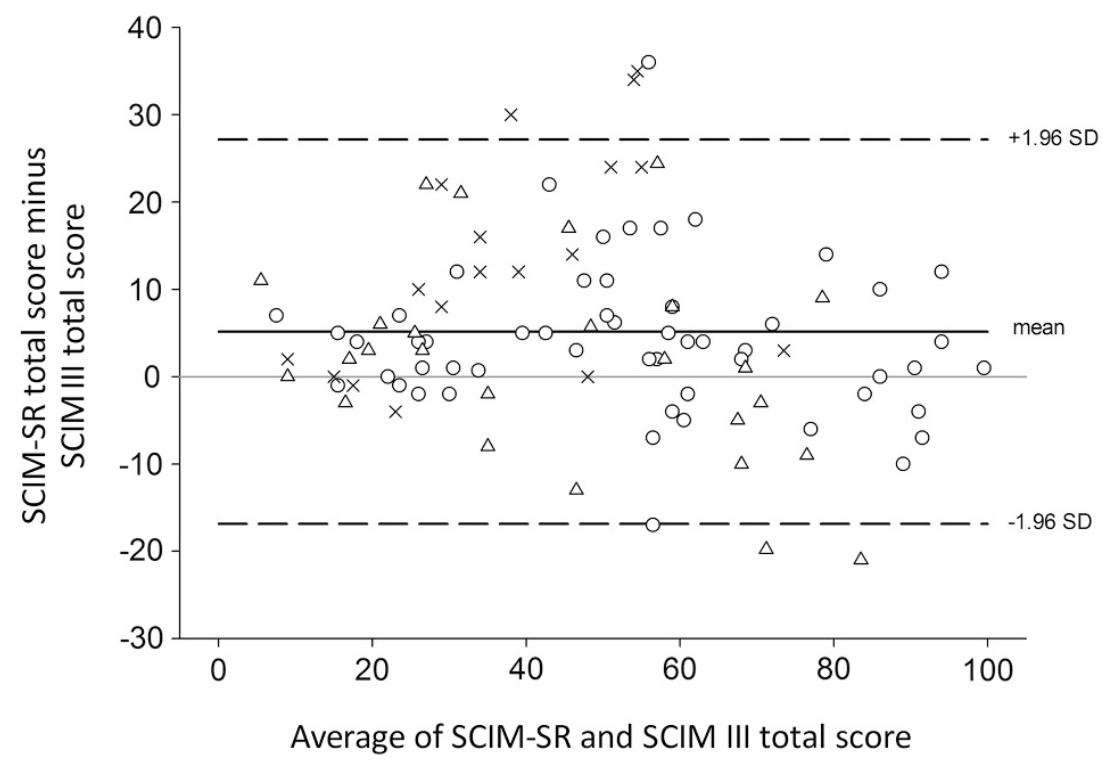

Figure 2 Bland-Altman plot for the total scores of SCIM III and SCIM-SR stratified by reason for admission. Missing values were accounted for by multiple imputation. $O$, persons in first rehabilitation; X, persons admitted because of a pressure sore and $\Delta$, persons admitted for other reasons. s.d., standard deviation. 
scores with age, gender, years of education and lesion characteristics were weak or inconsistent. Persons who got assistance with questionnaire completion showed less difference in scoring than those who filled in the questionnaire alone. The highest difference was found in persons hospitalized for pressure sores. The Bland-Altman plot for total scores stratified by reason for admission shown in Figure 2 confirms this finding.

\section{DISCUSSION}

The results of this study support the criterion validity of SCIM-SR as compared with SCIM III. Pearson correlation and ICC coefficients of the total and the subscale scores met the quality criterion of being above 0.7. ${ }^{18}$

Our results indicate systematically higher scores in SCIM-SR, especially in the mobility scale. This trend was not observed in similar studies that compared self-assessments by interview to observational scores of SCIM $\mathrm{II}^{8}$ or the Functional Independence Measure (FIM). ${ }^{19}$ In interviews, the interviewers might have interfered in case of uncertainties of patients, what could explain the absence of a systematic overestimation by respondents in those studies. ${ }^{8,19}$ We found somewhat smaller differences between SCIM III and SCIM-SR in participants who got assistance in questionnaire completion. Although it was not allowed to explain or give additional information, we cannot exclude that the presence of a researcher has influenced the results.

We observed an association between reason for admission and precision of SCIM-SR. Our findings suggest that persons hospitalized because of acute health conditions (e.g. pressure sores) do not report on their current situation, but take their 'habitual' level of independence as reference for self-assessment. To further improve the validity of the SCIM-SR, we suggest using a clearer introductory text in the questionnaire that stresses the relation to the current situation (see Appendix A for suggestion). We assume that SCIM-SR scores of communitydwelling SCI individuals in stable health conditions will show fewer differences in scoring. Further research is needed to show whether this assumption is justified. If systematic overestimation remained, it would be possible to adjust SCIM-SR results for it. However, in absence of valid data, we do not recommend such adjustments.

This study has several limitations. Only inpatients were included in this study, and this may limit the generizability of the results. Regarding the adaption of SCIM III to SCIM-SR, the comparability of item 6 (bladder management) is limited due to the impossibility to measure residual urine volume by self-report. Nevertheless, results indicate a high correlation between item 6 of SCIM-SR and SCIM III.

SCIM III was specifically designed to provide a clinical assessment of functional performances and studies approved the responsiveness of the instrument. ${ }^{3,20}$ In the current study, many participants were hospitalized due to health conditions such as pressure sores that reduced independence temporarily independent from the spinal cord lesion. Therefore, the design of our study did not allow assessing the sensitivity of SCIM-SR to improvement in functional level.

SCIM-SR was developed in English, based on the original English SCIM III version. ${ }^{3}$ Then, it was further refined and tested in German, and translated into French and Italian. However, only the German version has been validated and the present results might only hold true for this version. Conclusions on the validity of the English, French and Italian versions cannot be drawn and further validations of these language versions are encouraged. A Rasch analysis of the original SCIM III has been performed, ${ }^{3}$ but is not yet available for SCIM-SR
Besides these limitations, there are also some strengths. The study size of 99 persons is large for a validation study. ${ }^{18}$ The study population included a broad spectrum of individuals in terms of sociodemographic characteristics and functional independence. Further, recruitment of inpatients had the advantage that SCIM III data were collected by trained and experienced health professionals who know the included patients well and did not rely on information from the patient. We are confident that SCIM III scorings were sufficiently accurate to fulfill the requirements of a gold standard. Finally, missing values were not systematically distributed by age or level of education. We therefore assumed that the wording of the SCIM-SR questionnaire was sufficiently clear to be used for self-administration in patients without serious cognitive deficits.

\section{CONCLUSION}

Our findings support the criterion validity of SCIM-SR. As SCIM III is the only comprehensive disability measurement instrument specifically developed for persons with SCI, we believe that the present selfreport version will be a valuable tool for research in outpatient and community settings, as well as for resource-efficient assessment in hospitalized individuals with SCI.

\section{DATA ARCHIVING}

There were no data to deposit.

\section{CONFLICT OF INTEREST}

The authors declare no conflict of interest.

\section{ACKNOWLEDGEMENTS}

We are grateful to the clinical staff members of the Swiss Paraplegic Center (Nottwil) Cornelia Bühler, Andrea Bürgi, Astrid Eichholz, Sabine Felber, Kitty Pelt, Esther Peter, Daniel Ruckstuhl, Sylvia Seidl, Miriam van Schriek and Pascal Zehnder for their support with recruitment. We thank the research assistants Stefanie Bucher, Fabienne Michel, and Regula Sprecher for their help with recruitment. We express gratitude to Fin Biering-Sorensen, Mirjam Brach, Szilvia Geyh, Clive Glass and Gerold Stucki for their input in the development of SCIM-SR and Melissa Selb for the English check of SCIM-SR.

1 Catz A, Itzkovich M, Agranov E, Ring H, Tamir A. SCIM-spinal cord independence measure: a new disability scale for patients with spinal cord lesions. Spinal Cord 1997 35: 850-856

2 Anderson K, Aito S, Atkins M, Biering-Sørensen F, Charlifue S, Curt A et al. Functiona recovery measures for spinal cord injury: an evidence-based review for clinical practice and research. J Spinal Cord Med 2008; 31: 133-144.

3 Catz A, Itzkovich M, Tesio L, Biering-Sorensen F, Weeks C, Laramee MT et al. A multicenter international study on the Spinal Cord Independence Measure, version III: Rasch psychometric validation. Spinal Cord 2007; 45: 275-291.

4 Itzkovich M, Gelernter I, Biering-Sorensen F, Weeks C, Laramee MT, Craven BC et al. The Spinal Cord Independence Measure (SCIM) version III: reliability and validity in a multi-center international study. Disabil Rehabil 2007; 29: 1926-1933.

5 Anderson KD, Acuff ME, Arp BG, Backus D, Chun S, Fisher K et al. United States (US) multi-center study to assess the validity and reliability of the Spinal Cord Independence Measure (SCIM III). Spinal Cord 2011; 49: 880-885.

6 Hoenig H, Branch LG, McIntyre L, Hoff J, Horner RD. The validity in persons with spinal cord injury of a self-reported functional measure derived from the functiona independence measure. Spine 1999; 24: 539-543.

7 Itzkovich M, Tamir A, Philo O, Steinberg F, Ronen J, Spasser R et al. Reliability of the Catz-Itzkovich spinal cord independence measure assessment by interview and comparison with observation. Am J Phys Med Rehabil 2003; 82: 267-272.

8 Catz A, Itzkovich M, Steinberg F, Philo O, Ring $H$, Ronen J et al. Disability assessment by a single rater or a team: a comparative study with the Catz-Itzkovich spinal cord independence measure. J Rehabil Med 2002; 34: 226-230.

9 van Hedel HJ, Dietz V. Walking during daily life can be validly and responsively assessed in subjects with a spinal cord injury. Neurorehabil Neural Repair 2009; 23 $117-124$ 
10 Dorevitch M. The 'questionnaire' versus the 'direct observation' approach to functional assessment. Br J Rheumatol 1988; 27: 326-327.

11 Cieza A, Kirchberger I, Biering-Sorensen F, Baumberger M, Charlifue S, Post MW et al. ICF Core Sets for individuals with spinal cord injury in the long-term context. Spinal Cord 2010; 48: 305-312.

12 Kirchberger I, Cieza A, Biering-Sorensen F, Baumberger M, Charlifue S, Post MW et al. ICF Core Sets for individuals with spinal cord injury in the early post-acute context. Spinal Cord 2010; 48: 297-304.

13 Fekete C, Boldt C, Post M, Eriks-Hoogland I, Cieza A, Stucki G. How to measure what matters: development and application of guiding principles to select measurement instruments in an epidemiologic study on functioning. Am J Phys Med Rehabil 2011; 90: S29-S38.

14 Post MW, Brinkhof MW, von Elm E, Boldt C, Brach M, Fekete C et al. Design of the Swiss Spinal Cord Injury Cohort Study. Am J Phys Med Rehabil 2011; 90: S5-16.

15 Shrout PE, Fleiss JL. Intraclass correlations: uses in assessing rater reliability. Psychol Bull 1979; 86: 420-428.

16 Bland JM, Altman DG. Measuring agreement in method comparison studies. Stat Methods Med Res 1999; 8: 135-160.
17 Sterne JA, White IR, Carlin JB, Spratt M, Royston P, Kenward MG et al. Multiple imputation for missing data in epidemiological and clinical research: potential and pitfalls. BMJ 2009; 338: b2393.

18 Terwee CB, Bot SD, de Boer MR, van der Windt DA, Knol DL, Dekker J et al. Quality criteria were proposed for measurement properties of health status questionnaires. J Clin Epidemiol 2007; 60: 34-42.

19 Daving Y, Andren E, Nordholm L, Grimby G. Reliability of an interview approach to the functional independence measure. Clin Rehabil 2001; 15: 301-310.

20 Ackerman P, Morrison SA, McDowell S, Vazquez L. Using the Spinal Cord Independence Measure III to measure functional recovery in a post-acute spinal cord injury program. Spinal Cord 2010; 48: 380-387.

\section{(c)}

This work is licensed under the Creative Commons Attribution-NonCommercial-No Derivative Works 3.0

Unported License. To view a copy of this license, visit http:// creativecommons.org/licenses/by-nc-nd/3.0/

Supplementary Information accompanies the paper on the Spinal Cord website (http://www.nature.com/sc)

\section{APPENDIX A}

English version of SCIM III for self-report. The validated German version is available from the authors on request. Codes in square brackets indicate the scales used for comparison with SCIM III but are not printed in the participant questionnaire

For each item, please tick the box next to the statement that best reflects your current situation. ${ }^{\text {a }}$ Please refer your answers to the present situation, also if you currently face health problems that limit you in your current independence.

Please read the text carefully and only check one box in each section.

1. Eating and drinking

[0] $\square$ I need artificial feeding or a stomach tube.

[0] $\square$ I need total assistance with eating/drinking.

[1] $\square$ I need partial assistance with eating/drinking or for putting on/ taking off adaptive devices.

[2] $\square$ I eat/drink independently, but I need adaptive devices or assistance for cutting food, pouring drinks or opening containers.

[3] $\square$ I eat/drink independently without assistance or adaptive devices.

2A. Washing your upper body and head

Washing your upper body and head includes soaping and drying, and using a water tap.

[0] $\square$ I need total assistance.

[1] $\square$ I need partial assistance.

[2] $\square$ I am independent but need adaptive devices or specific equipment (e.g., bars, chair)

[3] $\square$ I am independent and do not need adaptive devices or specific equipment.

2B. Washing your lower body

Washing your lower body includes soaping and drying, and using a water tap.

[0] $\square$ I need total assistance.

[1] $\square$ I need partial assistance.

[2] $\square$ I am independent but need adaptive devices or specific equipment (e.g., bars, chair)

[3] $\square$ I am independent and do not need adaptive devices or specific equipment.
3A. Dressing your upper body

Dressing the upper body includes putting on and taking off clothes like t-shirts, blouses, shirts, bras, shawls, or orthoses (e.g., arm splint, neck brace, corset).

- Easy-to-dress clothes are those without buttons, zippers or laces.

- Difficult-to-dress clothes are those with buttons, zippers or laces.

[0] $\square$ I need total assistance.

[1] $\square$ I need partial assistance, even with easy-to-dress clothes.

[2] $\square$ I do not need assistance with easy-to-dress clothes, but I need adaptive devices or specific equipment.

[3] $\square$ I am independent with easy-to-dress clothes and only need assistance or adaptive devices or a specific setting with difficult-todress clothes.

[4] $\square$ I am completely independent.

3B. Dressing your lower body

Dressing the lower body includes putting on and taking off clothes like shorts, trousers, shoes, socks, belts, or orthoses

(e.g., leg splint).

- Easy-to-dress clothes are those without buttons, zippers or laces

- Difficult-to-dress clothes are those with buttons, zippers or laces

[0] $\square$ I need total assistance.

[1] $\square$ I need partial assistance, even with easy-to-dress clothes.

[2] $\square$ I do not need assistance with easy-to-dress clothes, but I need adaptive devices or specific equipment.

[3] $\square$ I am independent with easy-to-dress clothes and only need assistance or adaptive devices or a specific setting with difficult-todress clothes.

[4] $\square$ I am completely independent.

4. Grooming

Please think about activities such as washing hands and face, brushing teeth, combing hair, shaving, or applying make-up.

[0] $\square$ I need total assistance.

[1] $\square$ I need partial assistance.

[2] $\square \mathrm{I}$ am independent with adaptive devices.

[3] $\square$ I am independent without adaptive devices. 
5. Breathing

I need a respiratory (tracheal) tube ...

[0] $\square$ as well as permanent or from time to time assisted ventilation.

[2] $\square$ as well as extra oxygen and a lot of assistance in coughing or respiratory tube management.

[4] $\square$ as well as little assistance in coughing or respiratory tube management.

I do not need a respiratory (tracheal) tube ...

[6] $\square$ but I need extra oxygen or a lot of assistance in coughing or a mask (e.g., PEEP) or assisted ventilation from time to time (e.g., BIPAP)

[8] $\square$ and only little assistance or stimulation for coughing.

[10] $\square$ and can breathe and cough independently without any assistance or adaptive devices.

6. Bladder management

Please think about the way you empty your bladder. [Scoring of item 6: see Appendix B]

6A. Use of an indwelling catheter

[0] $\square$ Yes $\rightarrow$ Please go to question $7 A$

[1] $\square$ No $\rightarrow$ Please also answer questions $6 B$ and $6 C$.

6B. Intermittent catheterization

[0] $\square$ I need total assistance.

[1] $\square$ I do it myself with assistance (self-catheterization).

[2] $\square$ I do it myself without assistance (self-catheterization).

[3] $\square$ I do not use it.

6C. Use of external drainage instruments (e.g., condom catheter, diapers, sanitary napkins)

[0] $\square$ I need total assistance for using them.

[1] $\square$ I need partial assistance for using them.

[2] $\square$ I use them without assistance.

[3] $\square$ I am continent with urine and do not use external drainage instruments.

\section{Bowel management [Scoring of item 7: see Appendix C]}

7A. Do you need assistance with bowel management (e.g., for applying suppositories)?

[0] $\square$ Yes

[1] $\square$ No

7B. My bowel movements are...

[0] $\square$ irregular or seldom (less than once in 3 days).

[1] $\square$ regular (once in 3 days or more).

7C. Fecal incontinence ('accidents') happens ...

[0] $\square$ twice a month or more.

[1] $\square$ once a month.

[2] $\square$ not at all.

\section{Using the toilet}

Please think about the use of the toilet, cleaning your genital area and hands, putting on and taking off clothes, and the use of sanitary napkins or diapers.

[0] $\square$ I need total assistance.

[1] $\square$ I need partial assistance and cannot clean myself.

[2] $\square$ I need partial assistance but can clean myself.
[4] $\square$ I do not need assistance but I need adaptive devices (e.g., bars) or a special setting (e.g., wheelchair accessible toilet).

[5] $\square$ I do not need any assistance, adaptive devices or a special setting.

9. How many of the following four activities can you perform without assistance or electrical aids?

- turning your upper body in bed

- turning your lower body in bed

- sitting up in bed

- doing push-ups in wheelchair (with or without adaptive devices)

[0] $\square$ None, I need assistance in all these activities.

[2] $\square$ One

[4] $\square$ Two or three

[6] $\square$ All of them

10. Transfers from the bed to the wheelchair

[0] $\square$ I need total assistance.

[1] $\square$ I need partial assistance, supervision or adaptive devices (e.g., sliding board).

[2] $\square$ I do not need any assistance or adaptive devices.

[2] $\square$ I do not use a wheelchair.

11. Transfers from the wheelchair to the toilet/tub

Transferring also includes transfers from the wheelchair or bed to a toilet wheelchair.

[0] $\square$ I need total assistance.

[1] $\square$ I need partial assistance, supervision or adaptive devices (e.g., grab-bars).

[2] $\square$ I do not need any assistance or adaptive devices.

[2] $\square$ I do not use a wheelchair.

12. Moving around indoors

I use a wheelchair. To move around, ...

[0] $\square$ I need total assistance.

[1] $\square$ I need an electric wheelchair or partial assistance to operate a manual wheelchair.

[2] $\square \mathrm{I}$ am independent in a manual wheelchair.

I walk indoors and I ...

[3] $\square$ need supervision while walking (with or without walking aids).

[4] $\square$ walk with a walking frame or crutches, swinging forward with both feet at a time.

[5] $\square$ walk with crutches or two canes, setting one foot before the other.

[6] $\square$ walk with one cane.

[7] $\square$ walk with a leg orthosis(es) only (e.g., leg splint).

[8] $\square$ walk without walking aids.

13. Moving around moderate distances ( 10 to 100 meters)

I use a wheelchair. To move around, ...

[0] $\square$ I need total assistance.

[1] $\square$ I need an electric wheelchair or partial assistance to operate a manual wheelchair.

[2] $\square \mathrm{I}$ am independent in a manual wheelchair.

I walk moderate distances and I ...

[3] $\square$ need supervision while walking (with or without walking aids).

[4] $\square$ walk with a walking frame or crutches, swinging forward with both feet at a time. 
[5] $\square$ walk with crutches or two canes, setting one foot before the other.

[6] $\square$ walk with one cane.

[7] $\square$ walk with a leg orthosis(es) only (e.g., leg splint).

[8] $\square$ walk without walking aids.

14. Moving around outdoors for more than 100 meters

I use a wheelchair. To move around, ...
[0] $\square$ I need total assistance.
[1] $\square$ I need an electric wheelchair or partial assistance to operate a manual wheelchair.
[2] $\square \mathrm{I}$ am independent in a manual wheelchair.

I walk more than 100 meters and I ...

[3] $\square$ need supervision while walking (with or without walking aids).

[4] $\square$ walk with a walking frame or crutches, swinging forward with both feet at a time.

[5] $\square$ walk with crutches or two canes, setting one foot before the other.

[6] $\square$ walk with one cane

[7] $\square$ walk with a leg orthosis(es) only (e.g., leg splint).

[8] $\square$ walk without walking aids.

15. Going up or down stairs

[0] $\square$ I am unable to go up and down stairs.

I can go up and down at least 3 steps ...

[1] $\square$ but only with assistance or supervision.

[2] $\square$ but only with devices (e.g., handrail, crutch or cane).

[3] $\square$ without any assistance, supervision or devices.

16. Transfers from the wheelchair into the car

Transfers include also putting the wheelchair into and taking it out of the car.
[0] $\square$ I need total assistance.
[1] $\square$ I need partial assistance, supervision or adaptive devices.
[2] $\square$ I do not need any assistance or adaptive devices.
[2] $\square$ I do not use a wheelchair.

17. Transfers from the floor to the wheelchair
[0] $\square$ I need assistance.
[1] $\square$ I do not need any assistance.
[1] $\square$ I do not use a wheelchair.

additional instruction as suggested in the Discussion.

\section{APPENDIX B}

\section{Scoring of item 6 (bladder management) in SCIM-SR}

\begin{tabular}{cccc}
\hline \multicolumn{3}{c}{ SCIM-SR item } & Score in SCIM-SR \\
\cline { 1 - 2 } $6 \mathrm{~A}$ & $6 B$ & $6 C$ & \\
\hline 0 & Not relevant if $6 \mathrm{~A}=0$ & Not relevant if $6 \mathrm{~A}=0$ & 0 \\
1 & 0 & 0 & 6 \\
1 & 0 & 1 & 6 \\
1 & 0 & 2 & 6 \\
1 & 0 & 3 & 6 \\
1 & 1 & 0 & 6 \\
1 & 1 & 1 & 6 \\
1 & 1 & 2 & 6 \\
1 & 1 & 3 & 6 \\
1 & 2 & 0 & 6 \\
1 & 2 & 1 & 6 \\
1 & 2 & 2 & $\mathbf{9}$ \\
1 & 2 & 3 & 6 \\
1 & 3 & 0 & $\mathbf{6}$ \\
1 & 3 & 1 & 13 \\
1 & 3 & 2 &
\end{tabular}

\section{APPENDIX C}

\section{Scoring of item 7 (bowel management) in SCIM-SR}

\begin{tabular}{lccc}
\hline \multicolumn{2}{c}{ SCIM-SR item } & Score in SCIM-SR \\
\cline { 1 - 2 } $7 A$ & $7 B$ & $7 C$ & \\
\hline Not relevant if $7 B=0$ & 0 & Not relevant if $7 B=0$ & 0 \\
0 & 1 & 1 & 5 \\
0 & 1 & 2 & 5 \\
1 & 1 & 1 & $\mathbf{8}$ \\
1 & 1 & 2 & $\mathbf{1 0}$ \\
0 & 1 & 0 & $\mathbf{5}$ \\
1 & 1 & 0 & $\mathbf{5}$ \\
\hline
\end{tabular}

